\title{
Laser therapy in wound healing associated with diabetes mellitus - Review*
}

\author{
Raquel Gomes de Sousa ${ }^{1}$
}

\author{
Keila de Nazaré Madureira Batista ${ }^{1}$
}

DOI: http://dx.doi.org/10.1590/abd1806-4841.20163778

\begin{abstract}
The article discusses the results of a literature review on the application of low intensity laser therapy on the healing of wounds associated diabetes mellitus in the last 10 years. Objective: To determine the most effective parameter in healing wounds related to diabetes mellitus, as well as the most widely used type of laser. Methodology: consisted of bibliographic searching the databases Bireme, SciELO, PubMed/Medline and Lilacs by using the keywords related to the topic. Were selected from these keywords, papers discussing the use of laser on wounds associated with diabetes, published in the period 2005-2014, in Portuguese or English. Results: After analyzing the research, 12 studies consistent with the theme were selected. Conclusion: Based on this review, the studies that showed more satisfactory results in healing diabetic wounds were those who applied energy densities in the range of $3-5 \mathrm{~J} / \mathrm{cm} 2$, power densities equal to or below $0.2 \mathrm{~W} / \mathrm{cm} 2$ and continuous emission. The He-Ne laser with a wavelength of $632.8 \mathrm{~nm}$ was used more often.
\end{abstract}

Keywords: Diabetic foot; Foot ulcer; Laser therapy, low-level; Wound healing

\section{INTRODUCTION}

Diabetes mellitus (DM) comprises a set of metabolic diseases resulting from changes in the secretion and/or action of insulin produced by the pancreas. Its main feature is the hyperglycemia associated with dysfunction of various systems, such as cardiovascular, renal and nervous. ${ }^{1}$

After tissue injury, scarring occurs through four phases: hemostasis, inflammation, proliferation and remodeling. These phases involve a cascade of events that will add and promote the repair of the lesion. The action of growth factors such as VEGF (Vascular Endothelial Growth Factor), FGF (fibroblast growth factor) and TGF- $\beta$ (Transforming Growth Factor $\beta$ ) is essential since it stimulates fibroblast proliferation and collagen, as well as the neovascularization, important for scar formation. When any of these components is changed, there is a commitment of tissue repair and the wound becomes chronic. ${ }^{2}$

Received on 17.06 .2014

Approved by the Advisory Board and accepted for publication on 12.03.2015

* Study performed at

Department of Physiotherapy and Occupational Therapy, Universidade Federal do Pará (UFPA) - Belém (PA), Brazil.

Financial Support: None.

Conflict of Interest: None.

1 Universidade Federal do Pará (UFPA) - Belém (PA), Brazil.

C 2016 by Anais Brasileiros de Dermatologia 
In diabetic subjects, there is an endothelial dysfunction, which alters the performance of these cells, such as the proliferation, migration and angiogenesis ability, hampering the consolidation of this process. ${ }^{3}$ This dysregulation, associated with the presence of neuropathy and consequent reduction in sensitivity, predisposes the emergence of ulcers. ${ }^{4}$

The deficiency in the wound healing process is a complex problem not only for the diabetic patient and family, but also for the government, since the high-risk of the existing infection may culminate in the patient's limb and own life impairment, burdening the system with social security expenses. ${ }^{5-6}$

Due to this dysfunction, several studies have been conducted aiming to assist in wound healing of patients and to reduce morbidity and mortality caused by them. Among the reported therapeutic methods, there is the Low Level Laser Therapy (LLLT).

The low level laser therapy is considered an effective therapeutic method in wound healing when certain factors are properly observed, such as dosage, power input, time and interval between sessions. ${ }^{7}$ It promotes the reduction of the inflammatory phase, favoring the angiogenesis and the production of extracellular matrix components, as well as its organization. ${ }^{8-9}$

In addition to reducing the lesion area and accelerating the healing process, laser therapy has the advantage of being easily administered. These benefits assist in promoting patient quality of life and minimizing possible complications. ${ }^{10-11}$

Research conducted in vitro and in vivo, aiming at wound healing by LLLT, have different protocols. The types of low intensity lasers often found in the literature are Helium and Neon (He-Ne), Gallium-Aluminum-Arsenide (GaA1As) Aluminum-Gallium-Indium-Phosphorous (AlGaInP) and Gallium-Arsenide (GaAs). ${ }^{12}$ Parameters such as energy density, power, wave shape and length, beam and application time show wide divergence between studies. Dosage appears as one of the most disparate, ranging from 0.04 to $30 \mathrm{~J} / \mathrm{cm}^{2}{ }^{12,13}$

The densities used can often be inappropriate for the phase in which the wound is. In wound healing in diabetes, different doses will promote the stimulation or inhibition of this process. Thus, it is important to note, among the most commonly used protocols, which ones proved to be beneficial, so the effectiveness of photostimulation is not compromised. ${ }^{14}$

The random use of these parameters for the same purpose highlights the need for standardization in laser therapy. The objective of this study, therefore, was to check the most effective parameter in the healing of wounds associated with diabetes mellitus, as well as the most commonly used type of laser.

\section{METHODOLOGY}

We conducted a literature search in the databases Bireme, Scielo, Pubmed/ Medline and Lilacs through the combination of descriptors laser therapy, low level, diabetic foot, foot ulcer and wound healing. From these keywords, we selected articles addressing the use of low intensity laser in wounds associated with diabetes, published between 2005-2014, in Portuguese or English, with full text available for access. All articles that did not meet the above inclusion criteria, as well as literature reviews and studies analyzing laser therapy by light emitting diodes (LEDs), were excluded from this research.

\section{RESULTS}

After analysis of the research, we selected 12 studies compatible with the theme, depicted in table 1.

\section{DISCUSSION}

Among the selected studies, five presented experiments with He-Ne laser. Results obtained by the authors showed improvement in the healing process of wounds associated with DM, with increased collagen synthesis, fibroblast proliferation, angiogenesis and re-epithelialization. However, the parameters used were quite diverse, including studies using GaAlAs (4), AlGaInP (2) and GaAs (1).

Maiya et al (2005) used He-Ne laser at a dose of 4.8 $\mathrm{J} / \mathrm{cm}^{2}$ and a distance of $6 \mathrm{~mm}$ from the wound, applied for five days a week until complete healing in diabetic rats, and found an increase in the tissue repair rate. ${ }^{15}$ Moreover, Carvalho et al (2006), using daily an approximate dose $\left(4 \mathrm{~J} / \mathrm{cm}^{2}\right)$, showed that laser therapy can influence the percentage of collagen fibers, increasing their quantity both in diabetic and in control groups. ${ }^{16}$

In the study by Houreld and Abrahamse (2007), two energy densities were tested: $5 \mathrm{~J} / \mathrm{cm}^{2}$ for 37 minutes or 16 $\mathrm{J} / \mathrm{cm}^{2}$ for 2 hours. ${ }^{17}$ They found that the irradiation of $5 \mathrm{~J} /$ $\mathrm{cm}^{2}$ is capable of stimulating the expression of IL-6 (interleukin-6) and cell proliferation and migration of fibroblasts of diabetic wounds. On the other hand, diabetic wounds cells irradiated with $16 \mathrm{~J} / \mathrm{cm}^{2}$ demonstrated signs of cell damage, presenting inhibitory effect.

Maiya et al (2009) also compared the effect of different dosages (3-9 J/ $\left.\mathrm{cm}^{2}\right)$ and found that healing was significantly accelerated in the groups receiving irradiation of $3-6 \mathrm{~J} / \mathrm{cm}^{2}$ per day, being even more effective in the group irradiated with $4-5 \mathrm{~J} / \mathrm{cm}^{2} .{ }^{14}$ Doses between 7 and $9 \mathrm{~J} / \mathrm{cm}^{2}$ showed mild deceleration of the healing process and are considered bioinhibitories in diabetic wounds. Similarly, Hegde et al (2011) applied energy densities of $1-5 \mathrm{~J} / \mathrm{cm}^{2}$ and elected $3 \mathrm{~J} / \mathrm{cm}^{2}$ as the best one for wound healing. ${ }^{18}$

In contrast, Gungormus and Akyol (2009), using $\mathrm{GaAlAs}$ diode at a dose of $10 \mathrm{~J} / \mathrm{cm}^{2}$ with power density of 


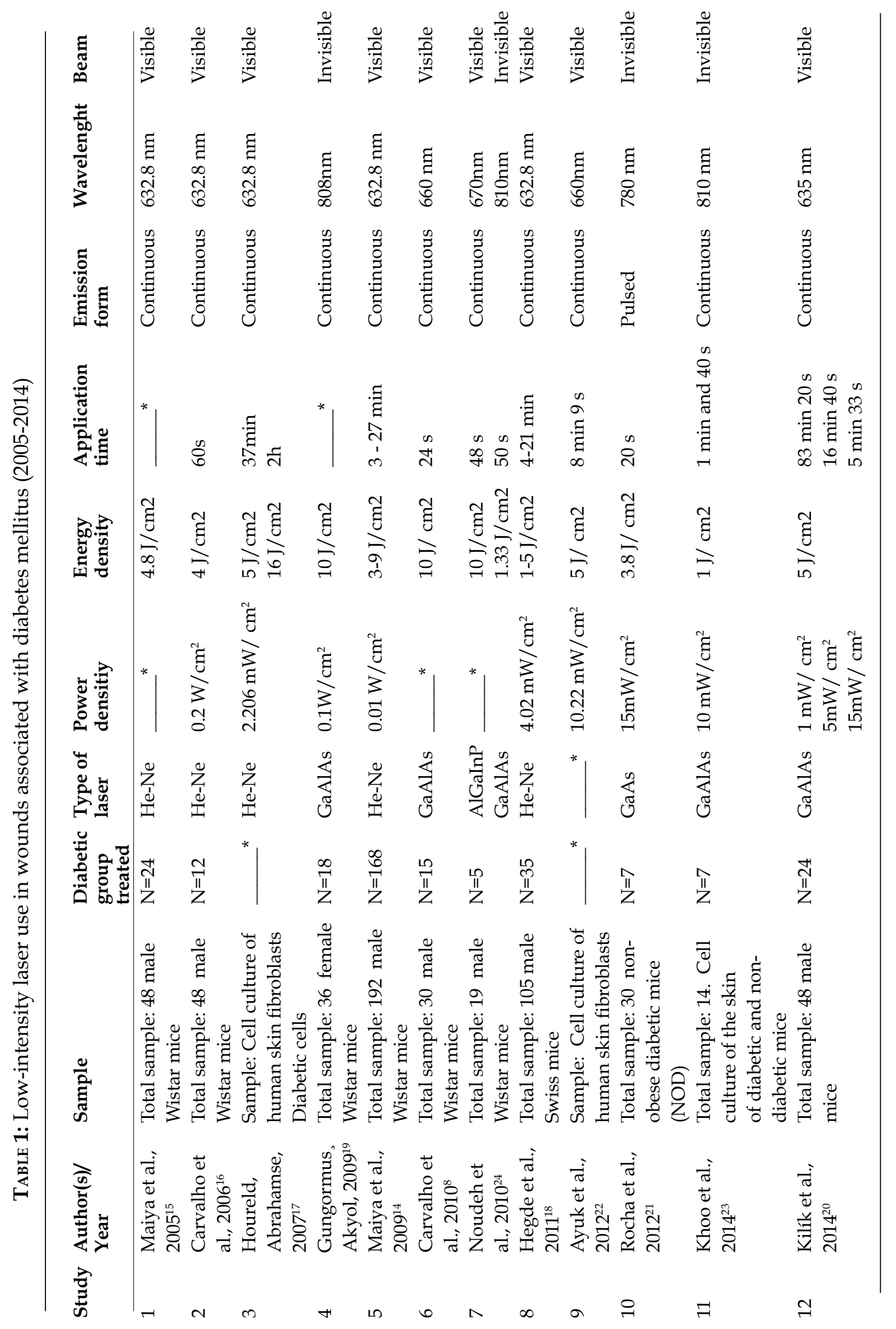


$0.1 \mathrm{~W} / \mathrm{cm}^{2}$, demonstrated an increase in re-epithelialization rate in the diabetic group treated with an interval of two days between applications. ${ }^{19}$ Benefits such as increased collagen and macrophages of diabetic wounds were also obtained with the same dosage in the study by Carvalho et al (2010), ${ }^{8}$ but using AlGaInP and application of $24 \mathrm{~s}$.

In order to verify the action of different power densities in the wound healing of diabetic and nondiabetic mice, Kilik et al (2014), after irradiation with GaAlAs and daily dose of $5 \mathrm{~J} / \mathrm{cm}^{2}$, observed a significant neovascularization in the groups irradiated with power densities of 5 and $15 \mathrm{~mW} / \mathrm{cm}^{2}$, as well as synthesis and organization of collagen fibers and reduced inflammatory response. ${ }^{20}$

Rocha et al (2012), also using a power of $15 \mathrm{~mW} / \mathrm{cm}^{2}$, but with GaAs diode at a dose of $3.8 \mathrm{~J} / \mathrm{cm}^{2}$, showed that low-intensity laser irradiation at an interval of 48 hours is able to downmodulate the expression of the enzyme cyclooxygenase 2, contributing to the control of the inflammatory response in skin lesions of NOD mice. ${ }^{21}$
The stimulation of the healing process has also been demonstrated in studies by Ayuk et al (2012) and Khoo et al (2014). ${ }^{22,23}$ Both used low-dose $\left(5: 01 \mathrm{~J} / \mathrm{cm}^{2}\right)$, with approximate power densities $\left(10.22 \mathrm{~mW} / \mathrm{cm}^{2}\right.$ and $\left.10 \mathrm{~mW} / \mathrm{cm}^{2}\right)$, but there was a wide variation in other parameters, such as application time and wavelength.

However, the study by Noudeh et al (2010), a combination of the AlGaInP and GaAlAs diodes, with a dose of $10 \mathrm{~J} / \mathrm{cm}^{2}(48 \mathrm{~s})$ and $1.33 \mathrm{~J} / \mathrm{cm}^{2}(50 \mathrm{~s})$, respectively, with an interval of three days between sessions, did not achieve significant results in the control group. ${ }^{24}$

\section{CONCLUSION}

Based on this review, the studies that presented better results in diabetic wounds healing were those that applied energy densities in the range of $3-5 \mathrm{~J} / \mathrm{cm}^{2}$, power densities $\leq 0.2 \mathrm{~W} / \mathrm{cm}^{2}$, and continuous emission. He-Ne laser with a wavelength of $632.8 \mathrm{~nm}$ was the most widely used. 


\section{REFERENCES}

1. Brasil. Ministério da Saúde. Secretaria de Atenção à Saúde. Departamento de Atenção Básica. Diabetes Mellitus. Brasília: Ministério da Saúde; 2006. 64 p. (Cadernos de Atenção Básica, n. 16) (Série A. Normas e Manuais Técnicos).

2. Enoch S, Grey JE, Harding KG. ABC of wound healing. Recent advances and emerging treatments. BMJ. 2006; 332:962-965.

3. Kolluru GK, Bir SC, Kevil CG. Endothelial Dysfunction and Diabetes: Effects on Angiogenesis, Vascular Remodeling, and Wound Healing. Int J Vasc Med. 2012; 2012:918267.

4. Houreld NN. Shedding Light on a New Treatment for DiabeticWound Healing: A Review on Phototherapy. Scientific World Journal. 2014; 2014:39841

5. Duarte N, Gonçalves A. Pé diabético. Angiol Cir Vasc 2011;7:65-79.

6. Rezende KF, Nunes MAP, Melo NH, Malerbi D, Chacra AR, Ferraz MB. Internações por Pé Diabético: Comparação entre o Custo Direto Estimado e o Desembolso do SUS. Arq Bras Endrocrinol Metab 2008; 52:523-530.

7. Silva DC, Plapler H, Costa MM, Silva SR, Sá Mda C, Silva BS. Low level laser therapy (AIGalnP) applied at $5 \mathrm{~J} / \mathrm{cm} 2$ reduces the proliferation of Staphylococcus aureus MRSA in infected wounds and intact skin of rats. An Bras Dermatol. 2013;88:50-5.

8. Carvalho Pde T, Silva IS, Reis FA, Perreira DM, Aydos RD. Influence of ingaalp laser $(660 \mathrm{~nm})$ on the healing of skin wounds in diabetic rats. Acta Cir Bras. 2010;25:71-9.

9. Colombo F, Neto Ade A, Sousa AP, Marchionni AM, Pinheiro AL, Reis SR. Effect of Low-Level Laser Therapy (660 nm) on Angiogenesis in Wound Healing: A Immuno histochemical Study in a Rodent Model. Braz Dent J. 2013;24:308-12.

10. Bonini-Domingos CR, Valente FM. Low-level laser therapy of leg ulcer in sickle cell anemia. Rev Bras Hematol Hemoter. 2012;34:65-6.

11. Rocha Júnior AM, Vieira BJ, Andrade LCF, Aarestrup FM. Effects of low-level laser therapy on the progress of wound healing in humans: the contribution of in vitro and in vivo experimental studies. J vasc bras 2007;6:257-65.

12. Beckmann KH, Meyer-Hamme G, Schröder S.LowLevel Laser Therapy for the Treatment of Diabetic Foot Ulcers: A Critical Survey. Evid Based Complement Alternat Med. 2014;2014:626127.

13. Piva JA, Abreu EM, Silva Vdos S, Nicolau RA. Ação da terapia com laser de baixa potência nas fases iniciais do reparo tecidual: princípios básicos. na Bras Dermatol. 2011;86:947-54.

14. Maiya AG, Kumar P, Nayak S. Photo-stimulatoryeffectoflowenergyhelium-neon laser irradiation on excisional diabetic wound healing dynamics in wistar rats. Indian J Dermatol. 2009;54:323-9.

15. Maiya GA, Kumar P, Rao L. Effect of Low Intensity Helium-Neon (He-Ne) Laser Irradiation on DiabeticWound Healing Dynamics. Photomed Laser Surg. 2005;23:187-90.

16. Carvalho PT, Mazzer N, dos Reis FA, Belchior AC, Silva IS. Analysis of the influence of low-power HeNe laser on the healing of skin wounds in diabetic and non-diabetic rats. Acta Cir Bras. 2006;21:177-83.

17. Houreld N, Abrahamse H. Irradiation with a $632.8 \mathrm{~nm}$ Helium-Neon Laser with $5 \mathrm{~J} /$ $\mathrm{cm} 2$ Stimulates Proliferation and Expression of Interleukin- 6 in Diabetic Wounded Fibroblast Cells. Diabetes Technol Ther. 2007;9:451-9.

18. Hegde VN, Prabhu V, Rao SB, Chandra S, Kumar P, Satyamoorthy K, et al. Effect of laser dose and treatment dchedule on excision wound healing in diabetic mice. Photo chemPhotobiol. 2011;87:1433-41.

19. Güngörmüş $M$, Akyol UK. Effect of Biostimulation on Wound Healing in Diabetic Rats. Photomed Laser Surg. 2009;27:607-10.

20. Kilík R, Lakyová L, Sabo J, Kruzliak P, Lacjaková K, Vasilenko T, et al. Effect of Equal Daily Doses Achieved by Different Power Densities of Low Level Laser Therapy at $635 \mathrm{~nm}$ on Open Skin Wound Healing in Normal and Diabetic Rats. Biomed Res Int. 2014;2014:269253.

21. Rocha CLJV, Rocha Júnior AM, Aarestrup BJV, Aarestrup FM. Inibição da expressão de ciclooxigenase 2 em feridas cutâneas de camundongos NOD submetidos à terapia a laser de baixa intensidade. J Vasc Bras. 2012;11:175-181.

22. Ayuk SM, Houreld NN, Abrahamse H. Collagen Production in Diabetic Wounded Fibroblasts in Response to Low-Intensity Laser Irradiation at 660nm. Diabetes Technol Ther. 2012;14:1110-7.
23. Khoo NK, Shokrgozar MA, Kashani IR, Amanzadeh A, Mostafavi E, Sanati H, et al. In vitro Therapeutic Effects of Low Level Laser at mRNA Level on the Release of Skin Growth Factors from Fibroblasts in Diabetic Mice. Avicenna J Med Biotechnol. 2014;6:113-8.

24. JahangiriNoudeh $Y$, Shabani M, Vatankhah N, Hashemian SJ, Akbari K. A Combination of 670nm and 810nm Diode Lasers for Wound Healing Acceleration in Diabetic Rats. Photomed Laser Surg. 2010;28:621-7.

\author{
MAILING ADDRESS: \\ Raquel Gomes de Sousa \\ Augusto Corrêa St., 01 - Portão 4 \\ Cidade Universitária José Silveira Neto \\ Faculdade de fisioterapia e terapia ocupacional \\ Setor Saúde \\ 66075-110 Guamá, PA \\ Email: raquelgomes.rg@gmail.com
}

How to cite this article: Sousa RG, Batista KNM. Laser therapy in wound healing associated with diabetes mellitus - Review. An Bras Dermatol. 2016;91(4):489-93. 